\title{
The Impact of Dynamic Capabilities on Organizational Effectiveness
}

\author{
Mohanad Ali KAREEM \\ Kaposvár University, Kaposvár, Hungary. \\ mohannadali25@gmail.com \\ Alaa Abdulameer Ahmed ALAMEER \\ Middle Technical University, Baghdad, Iraq \\ alaameer72@mtu.edu.iq
}

\begin{abstract}
This paper aims to investigate the impact of dynamic capabilities constructs i.e. sensing capability, learning capability, and reconfiguration capability on organizational effectiveness in the selected Iraqi public universities context. This study adopted the survey method to collect primary data. An online questionnaire was distributed to around 342 employees, out of which 215 completed questionnaires were obtained. The data were collected during the period from 02- 08-2018 to 03-10-2018. The reliability and validity of the dimensions are assessed through confirmatory factor analysis (CFA) and the hypotheses are tested by using structural equation modeling SEM. The analytical results indicate that sensing capability does not have a positive impact on organizational effectiveness while learning capability and reconfiguration capability have a positive impact on organizational effectiveness. Thus, this study provides a better understanding of the effects of dynamic capabilities. The results of this study have the potential to help the decisionmakers of universities to develop learning capability and reconfiguration capability, in turn, universities will be able to achieve superior organizational effectiveness.
\end{abstract}

Keywords: sensing capability, learning capability, reconfiguration capability, organizational effectiveness.

\section{Introduction}

The global competition and the rapid growth of the knowledge economy in highly changeable environment has encouraged the organizations to develop a paradigm to understand how to sustain their competitiveness and achieve superior organizational effectiveness. One of the vital efforts to address that challenges is the dynamic capabilities approach (Rao, 2016). The concept of dynamic capabilities is a relatively novel concept, which has provided foundations of how organizations are renewed its internal and external competences to address to environmental turbulence. The dynamic capabilities have emerged from the resource-based view (RBV) of the firm which explains that unique, inimitable and rare resources are core source of superior performance, and achieve sustained competitive advantage (Barney, 1991; Teece al. 1997; Eisenhardt \&Martin, 2000). Teece, al. (1997) defined dynamic capabilities as the firm's ability to integrate, build, and reconfigure internal and external competencies to address rapidly changing environments. Dynamic capabilities play key role in matching organization's external opportunities with internal strengths through the integrate, build, and reconfigure of internal resources, they ensure sustainable competitive advantages and maintained organizational effectiveness (Teece, 2007). In the last decade or so, this significance of dynamic capabilities has attracted many of researchers (Zollo and Winter, 2002; Li and Liu, 2014; Zahra et al., 2006 and Barreto, 2010). Some researchers investigated empirically the relationship between dynamic capabilities and firm performance (Danneels, 2012; Wilden et al.,2008 and Protogerou et al.,2012). Despite the increased 
attention on dynamic capabilities but, there is still confusion about how dynamic capabilities influence organizational effectiveness.

This study aims to investigate the relationship of dynamic capabilities and organizational effectiveness in the selected Iraqi public universities context. A few studies that explored dynamic capabilities in higher education's institutes context (Gallardo and Navarro,2003; Takahash et al.,2016; Bejinaru,2017), but no one has specifically dealt with examine how dynamic capabilities effect on organizational effectiveness. This study tries to address this gap through proposing an empirical model that dynamic capabilities constructs i.e. sensing capabilities, learning capabilities and reconfiguration capabilities have a positive influence on organizational effectiveness. This article contributions to the literature in two ways. First, it reviews the dynamic capabilities concept using three dimensions i.e. sensing capabilities, learning capabilities and reconfiguration capabilities may that contributions in further investigation of the nature and dimensionality of dynamic capabilities and their role in the business context. Second, it exams empirically the link between dynamic capabilities and organizational effectiveness in the selected Iraqi public universities context.

The remainder of the article is organized as follows: the first section presents the objectives, research questions, hypotheses and proposed model of the study. Second section presents the literature review. Third section presents the research methodology. Fourth section presents the data analysis and results. The last section presents discussion of the findings including theoretical and practical implications, study limitations and future research.

\section{Literature review \\ Dynamic capabilities}

The concept of dynamic capabilities has emanated from the resource-based view (RBV) for its ability to meet rapid environmental changes (Teece, 2007). Since the initial introduction of the concept by (Teece et al., 1997) is gaining greater attention in the literature. He defines dynamic capabilities as a firm's ability to integrate, build and reconfigure internal and external competencies to address rapidly changing environments. Further, (Eisenhardt \& Martin, 2000) describe dynamic capabilities are a set of specific and identifiable processes such as product development, strategic decisionmaking, and alliancing. Dynamic capabilities are distinctive in their details and pathdependent on their emergence; they have significant commonalities across firms. (Zollo and Winter, 2002) define dynamic capabilities as a learned and stable collective processes enable organization systematically creates and modifies its operational activities in order to improve effectiveness. (Zahra \& George, 2002) state that dynamic capabilities are basically changing-oriented capabilities that enable firms to renew and reconfigure their resource base to meet evolving customer demands and competitor strategies. More recent $($ Rao,2016) describes dynamic capabilities as firm's capability to manage alliances, learn, integrate and reconfigure resource base to address the changing business conditions.

The literature discussed on dynamic capabilities is confused with discrepancies and overlapping definitions. Several scholars suggest to better understand the nature of dynamic capabilities is distinguish between dynamic and operational capabilities. (Helfat et al., 2007) distinguish between dynamic and operational capabilities. They state that operational capabilities firm ability to perform their everyday functional activities, while dynamic capabilities are used to maintain the current status. (Teece, 2007) explains that operational capabilities are organizations ability to maintain its technical competences by 
ensuring the efficiency of its operational activities, while dynamic capabilities help a firm's to sustain evolutionary competences by enabling the build, renewal, and reconfiguration of its resource base, thereby achieve sustainable competitive advantage. In results, dynamic capabilities are organization capacity enabling the creation, extension, and modification of its operational capabilities systematically (Protogerou et al.,2011).

The dynamic capabilities in the universities context play a vital role in building capacity to respond to social needs, efficiency, effectiveness, and quality. An environmental changes and greater social demands are forcing universities to implement a process of change that requires continuous improvement and the creation of dynamic capabilities (Gallardo \& Navarro,2003). In the rapidly changing educational circumstances, educational leadership needs to develop dynamic capabilities by integrating and reconfiguring their internal and external resources and competencies to address environmental changes (Johara, 2018). (Takahashi et al.,2016) confirm empirically that the dynamic capabilities impact on organizational performance when mediated by marketing capability in the context of private HEIs in Brazil.

\section{Dynamic capabilities contribution to organizational effectiveness}

The impact of dynamic capabilities on organizational effectiveness has been an attractive issue among scholars. However, the way that dynamic capabilities affect organizational effectiveness is still under investigation. Also, the empirical studies on this linkage are limited. This article views different opinions exist as to whether dynamic capabilities affect organizational effectiveness and performance. (Helfat \& Peteraf, 2009) argue that dynamic capabilities do not directly affect organizational effectiveness and performance. They affect organizational effectiveness and performance indirectly by integrating and reconfiguring resources to address the environmental turbulence or to create internal and external change (Eisenhardt and Martin, 2000; López, 2005). Dynamic capabilities create and define the firm's individual resource configuration, which shapes the firm's competitiveness and therefore performance (Galunic \& Eisenhardt, 2001). Dynamic capabilities are the key to adoption to the competitive intensity and strive for survival that leads to enhancing the effectiveness of organizational performance (Wilden et al, 2013). Dynamic capabilities positively affect organizational effectiveness and performance in different ways; dynamic capabilities can link the resource base with changing environments (Teece et al., 1997). Create a market change (Eisenhardt and Martin, 2000). Dynamic capabilities improve the effectiveness, speed, and efficiency of organizational responses to environmental requirements and, in turn, essentially support superior performance (Chmielewski and Paladino, 2007). Also, dynamic capabilities i.e. sensing, learning and reconfiguration may can support make decisions within the organization which has the potential to enhance organizational effectiveness and performance (Eisenhardt and Martin, 2000; Teece, 2007).

Zollo \& Winter, (2002) state that dynamic capabilities enable organizations to acclimate their operating routines constantly to changing environmental turbulence, and allowing them to improve their operating routines performance and survival in competition. Likewise, (Schreyögg \& Kliesch-Eberl, 2007) argue that dynamic capabilities may enhance the effectiveness of operating routines by enabling firms to better seize opportunities and overcome threats over their competitors. Dynamic capabilities may influence organizational effectiveness and performance through employing sensing capability, organizations may detect new and technically significant opportunities, discover the shifts of suppliers and competitors, and identify risks in a timely manner (Wilhelm et al.,2015). By using learning capability, organizations can generate 
new knowledge; thus, to restore operational capabilities with new knowledge, in turn, achieve better operating-routine goals (Helfat et al,2007). Finally, by employing reconfiguring capability enable organizations to discard, modify, or rebuild in order to adjust their operating routines to new conditions (Teece et al.,1997).

In sum, dynamic capabilities contribute to organizational effectiveness through an effective modification of existing operating routines, enabling the organization to adopt environmental changes by way of sensing environmental conditions, learning response patterns and reconfiguring operating routines. Therefore, use dynamic capabilities enhance organizational effectiveness and performance.

The impact of dynamic capabilities on organizational effectiveness and performance depends on the organizational context. Both the internal and external contexts are significant in the understanding effect of dynamic capabilities. Internal fit describes the congruent between dynamic capabilities and organizational structure, and external fit, characterized in matching dynamic capabilities and levels of competitive intensity, represent to fundamental requirements that support the role of dynamic capabilities in affecting organizational effectiveness and performance (Wilden et al.,2013).

Dynamic capabilities are a multidimensional construct of interrelated and complementary dimensions (Barreto, 2010; Teece, 2007). In order to explore in an integrated way, the impact of dynamic capabilities on organizational effectiveness this study determined the dynamic capabilities in three measured dimensions: sensing capability, learning capability, and reconfiguration capability. Sensing capability measures the organization's ability to recognize shifts in the environment to discover opportunities that could impact the organization's business. Learning capability measures the organization's ability to create internal knowledge, to acquire external knowledge, and to assimilate internal and external knowledge through knowledge sharing. Reconfiguration capability measures the organization's ability to create new capabilities, reconfigure assets and organizational structures to address the markets and technologies changes.

\section{Sensing capability and organizational effectiveness}

The rapid changes in environment and market, that make the challenge to predict and recognize the paths of future development. New idea, information and knowledge may create opportunities for development. Therefore, sensing capability is firm's ability to constantly scan, search, and explore opportunities across technologies and markets (Teece, 2007). Likewise, (R. M. Henderson \& Clark, 1990) describe sensing capability as the firm's ability to discover new opportunities, scan environment, response to competitive strategies and evaluates the competitive position. The firm must have the capability to reconfigure its resource base by sensing the shifts in the environment effectively and respond accordingly that enable the firm to achieve a sustainable competitive advantage (Rehman \& Saeed, 2015).

The sensing capability also involves a better understanding of the latent demand, evaluates of industries and markets, and the likely responses of suppliers and competitors. When firms discover a new opportunity, sensing capability not only help firms to understand which technologies should be explored but also enable them to detect which market segments should be targeted (Teece et al.,1997). Sensing capability comprises of three basic processes: First, generates market information, as it relates to the identification of customer needs, respond to marketing trends and identify market opportunities. Second, interpret the gathered market information. Third, responding to market information (Day, 2011; Janssen et al., 2015). 
Sensing capability is an initial element of dynamic capabilities, as it is the point where a possible need or opportunity to build, extend or modify existing capabilities are identified based on changes in the internal and external business environment or if the organization can address the changes based on the current capability endowment (Capron \& Mitchell, 2009). Sensing, thus, relates to both the firm's capability to recognize changes in the external environment that could affect the organization's business and the ability to identify to what extent the organization might respond with its current capability endowment, or to what extent the development of new capabilities is necessary (Barreto, 2010).

In such way, the sensing capability in educational organizations comprises of external dimensions (environment) and internal dimensions (institution performance) assessment to analytically filter, shape, sense and calibrate the opportunities. Collaboration readiness, learning, and training (analytical skills and individual capacities), performance assessment and environmental assessment also help to capture or sense the opportunity (Labanauske and Nedzinskas,2017). Sensing capability refers to universities' ability to detect opportunities in the internal and external environment (Gratton \& Ghoshal, 2005). But, the operational performance such as research \& development, financial and human investment as well as university's ability to scanning, creating and learning are still depend on the university's management to implement the appropriate strategy to coordinate them. Based on the above discussion, the first hypothesis can be derived as follows:

H1: Sensing capability has a significant impact on organizational effectiveness.

\section{Learning capability and organizational effectiveness}

Learning capability refers to the firm ability to generate internal knowledge, to acquire external knowledge, and to integrate internal and external knowledge through knowledge sharing (Zahra \& George, 2002). The notion of learning is the ability to quickly acquiring or creating specific knowledge necessary to seize the identified opportunities (Eisenhardt \& Martin, 2000). To seize opportunities firms, need to implement interrelated strategic choices and investment decisions. In order to make significative decisions to address opportunities and threats, it is necessary that firms reach a new state of knowledge in order to understand the alternatives at hand and the interrelatedness of the factors involved (Teece, 2007). Learning capability focuses on the use of market information to generate new knowledge; thus, it is the ability to restore operational capabilities with new knowledge (Kindström et al., 2013). Learning capability refers to the firm's ability to ensure the efficiency and effectiveness of its operational activities by acquiring, changing and reconfiguring resources in cope with environmental changes (Lavie, 2006).

Learning capability composes four basic abilities: first, the ability to acquire knowledge, as it relates to acquiring new knowledge. Second, the ability to realize knowledge as it relates to the clarification of knowledge. Third, the ability to transform knowledge, as it relates to creativity in problem-solving, brainstorming, and creative thinking. Fourth, the ability to use knowledge, as it relates to the practice of new initiatives and seize opportunities in addition to the renewal of operational capabilities ( $\mathrm{Li}$ and Liu, 2014; Qiang et al., 2013). Based on the above contribution, the second hypothesis can be derived as follows:

H2: Learning capability has a significant impact on organizational effectiveness. 


\section{Reconfiguration capability and organizational effectiveness}

A key to sustaining long-term competitive advantage is it necessary for an organization to recombine and to reconfigure assets and organizational structures to cope with the change of the markets and technologies. Furthermore, to sustain superior firm performance the enterprise has to develop corporate culture, design reward systems and retain committed talent (Teece, 2007). Reconfiguration capability involves activities such redeploying and recombining resources thus, reconfiguration capability enhances continuous development and can also become a mechanism for firms to acquire new resources and seize innovation benefits (Karim \& Capron, 2016). Reconfiguration capability refers to the recombination and transformation of existing resources that enable the firm's to address the changes in market conditions (Teece et al., 1997). Reconfiguration capability includes two basic processes: first, create capabilities which can be built internally or can be acquired from external sources. Building capabilities internally relate to the transformation of existing capabilities, i.e. to change the form, shape, or appearance of capabilities existing within the firm (Carlile, 2004). Acquiring capabilities refers to gain capabilities from outside sources, e.g. licensing, purchasing contracts, alliancing, mergers and acquisitions of firms or parts of firm (Capron \& Mitchell, 2009; Lavie, 2006). Second, integrate capabilities refers to an engaging, connecting and linking of new capabilities into the organization with existing resources and capabilities (Iansiti \&Clark, 1994; Teece et al., 1997).

Therefore, the reconfiguration capability enables the firm to discard, modify, or rebuild organizational routines and practices in order to make operations more efficient and effective and, in turn, enhance the organizational effectiveness. In such a way, the key to the educational organization's successful effectiveness and performance depends on its ability to demonstrate effective leadership and implement appropriate governance for transformation. Also, the flexibility of business models, reconfigure assets, and routines and organizational structures ensure the superior performance and effectiveness. Based on the above contribution, the third hypothesis can be derived as follows:

H3: Reconfiguration capability has a significant impact on organizational effectiveness.

Considering the above-mentioned hypothesizes, the study proposed the following model as a conceptual model of this paper as it is showing in figure 1

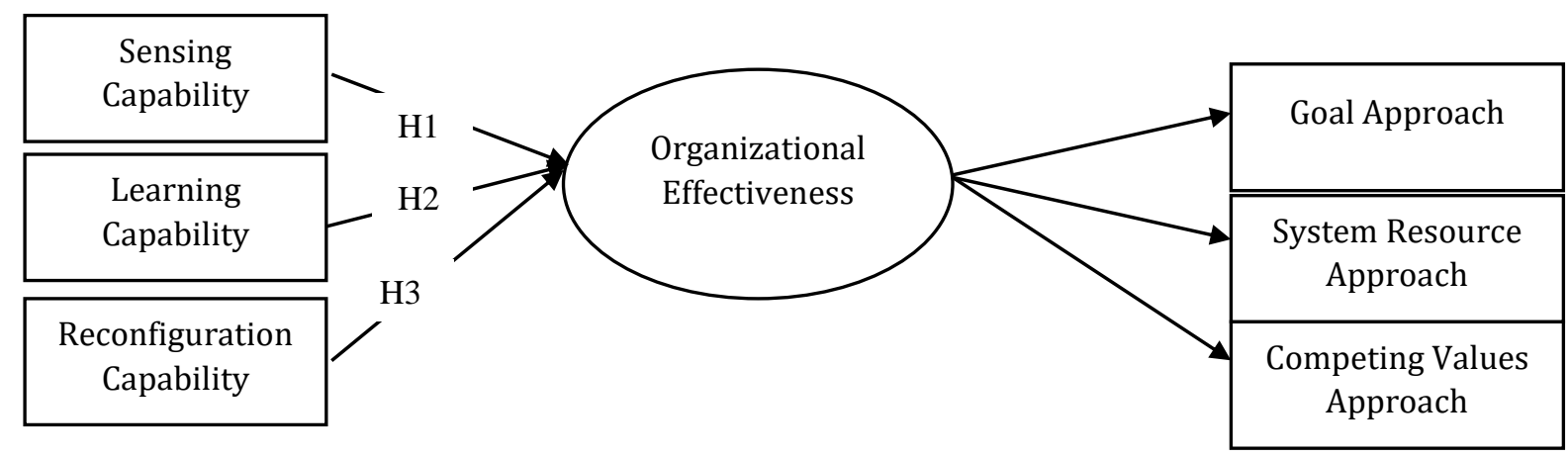

Figure 1. A proposed research model

Source: Authors' own research contribution

\section{Research Methodology}

\section{Research design, sampling and data collection}

This research employed a quantitative design. A quantitative design is appropriate to use in hypotheses testing of the relationship between independent and dependent variables 
(Sekaran \& Bougie, 2013). The purpose of this quantitative design study was to examine the impact of dynamic capabilities i.e. sensing capability, learning capability, and reconfiguration capability on organizational effectiveness. The study took place in top ten Iraqi public universities. This research used the survey method to collect the primary data because it is considered an economical and efficient method to gather quantitative data concerned to a given population for the purpose of generalizing the result. The data were collected during the period from 02- 08-2018 to 03-10-2018. An online questionnaire was used as a data collation instrument (see table 2 and appendix 1). According to (Grohmann \& Kauffeld, 2013) questionnaire is often used while adapting the survey method. The questionnaire was created by the google-forms tool, which is commonly used by researchers for collecting data. The web-based questionnaires were distributed through E-mail designed to collect the relevant data from the selected public universities of Iraq. The sample is including a number of deans, heads of departments, faculty members, and administrative staff which seems to provide a corresponding sample for conducting data collecting and analyzing. The questionnaire was distributed to around 342 employees, out of which 215 completed questionnaires were obtained, with a response rate of $62.86 \%$ of the which sufficient for further analysis as suggested by (Sekaran and Bougie, 2010) argues that a response with $30 \%$ is enough for further study. The demographic data of the respondents are shown in table 1.

Table 1. The demographic data of the respondents

\begin{tabular}{|l|l|l|l|}
\hline Item & & Frequency & Percentage \\
\hline Gender of the respondent & Male & 165 & 76.74 \\
\cline { 2 - 4 } & Female & 50 & 23.25 \\
\hline \multirow{4}{*}{ Age of the respondent } & $20-30$ years & 34 & 15.81 \\
\cline { 2 - 4 } & $31-40$ years & 96 & 44.65 \\
\cline { 2 - 4 } & $41-50$ years & 65 & 30.23 \\
\cline { 2 - 4 } & $51-60$ years & 14 & 6.51 \\
\cline { 2 - 4 } & More than 61 years & 6 & 2.79 \\
\hline \multirow{5}{*}{ Educational achievements } & Dean & 10 & 25.65 \\
\cline { 2 - 4 } & Head of department & 55 & 36.74 \\
\cline { 2 - 4 } & Faculty member & 79 & 33.02 \\
\cline { 2 - 4 } & Administrative staff & 71 & 12.93 \\
\hline & Bachelor's Degree & 26 & 40.46 \\
\cline { 2 - 4 } & Master's Degree & 87 & 14.44 \\
\cline { 2 - 4 } & Ph.D. Degree & 102 & 29.30 \\
\hline Work Experience & Less than 5 years & 31 & 41.39 \\
\cline { 2 - 4 } & 5-10 years & 63 & 14.88 \\
\cline { 2 - 4 } & $11-20$ years & 89 & \\
\cline { 2 - 4 } & More than 21 years & 32 & \\
\hline
\end{tabular}

Source: Authors' own research results

Table 1 presents the demographic data of the respondents. Out of the 215 respondents, $(76.74 \%)$ were males and $(23.25 \%)$ females. The majority of the respondents $(44.65 \%)$ were in the age category within 31-40 years. Most of the respondents at $(36.74 \%)$ were faculty members designation. The majority of the respondents (47.44\%) were holders Ph.D. degree while (40.46\%) were holders master's degree and $(12.93 \%)$ were holders bachelor's degree. A little lower than half of the respondent $(41.39 \%)$ had work experience 11-20 years.

\section{Instrumentation development}

The questionnaire comprises of two sections. Section one collects participant \& institutional background information of the respondents such as gender, age, the 
position held, educational attainment, work experience, and organization size. Section two includes items are designed to measure the variables of the study by using a comparative seven-point Likert-type scale ranging from 1-7, in which, 1 = strongly disagree, 7 = strongly agree. Furthermore, 15 items are designed to measure dynamic capabilities constructs: sensing capability, learning capability, and reconfiguration capability and, 12 items are designed to measure the organizational effectiveness constructs which are goal approach, system resource approach, and competing values approach. Schumacker and Lomax (2010) state that a sample size of 200- 250 and at least five subjects per variable would be sufficient to ensure a reasonable level of bias in SEM. Also, Cronbach 's alpha coefficient was used to evaluate the internal consistency of the scales where Cronbach 's alpha coefficient for all the constructs ranges between 0.874 and 0.962 and it is considered acceptable which indicates that all the items are internally consistent. Table (2) shows detailed information regarding the variables, sources, number of the items and Cronbach's alpha as follows:

Table 2 the study measures in regard to the sections of the questionnaire, sources, and Cronbach's alpha

\begin{tabular}{|c|c|c|c|c|}
\hline Sections & Name of the variable & Source & $\begin{array}{l}\text { Number } \\
\text { of items }\end{array}$ & $\begin{array}{l}\text { Cronbach's } \\
\text { alpha }\end{array}$ \\
\hline $\begin{array}{c}\text { section } \\
\text { one }\end{array}$ & $\begin{array}{l}\text { participant \& institutional } \\
\text { background information }\end{array}$ & Researcher developed & 9 & \\
\hline \multirow{6}{*}{$\begin{array}{l}\text { Section } \\
\text { two }\end{array}$} & Sensing capability & \multirow{3}{*}{$\begin{array}{l}\text { Teece et al. ,1997);( Eisenhardt } \\
\text { and Martin ,2000);( } \\
\text { Nieves\& Haller,2014) }\end{array}$} & 5 & 0.924 \\
\hline & Learning capability & & 5 & 0.962 \\
\hline & Reconfiguring capability & & 5 & 0.938 \\
\hline & Goal approach & (Banat,2002) & 4 & 0.931 \\
\hline & System resource approach & (Abu El Khair, 2016) & 4 & 0.874 \\
\hline & Competing values approach & $\begin{array}{l}\text { (Gold et al., 2001), (Rahman et } \\
\text { al., 2013) }\end{array}$ & 4 & 0.936 \\
\hline
\end{tabular}

Source: Authors' own research results

\section{Data analysis procedure}

Data analysis was conducted to address the research questions, objectives and hypotheses. Statistical Package for Social Science (SPSS) version 23 and the Analysis of Moment Structures (AMOS) software version 24 were used for analyzing data. Before conducting data analysis, the data preparation was done on the completed questionnaires by editing, coding, entering and cleaning the data. Descriptive statistics such as the frequency and percentage, mean, standard deviation, were used to provided data summarization of demographic characteristics of respondents. Also, the Pearson correlation coefficient was used to describe the correlations among the variables. To purify the instrument items, confirmatory factor analysis (CFA) was carried out to assess the validity and reliability of the instrument by using convergent and discriminant validity. Also, Cronbach's Alpha was used to examine the reliability of the scale items. The overall model fit was assessed using seven goodness-of-fit indices, namely the chisquare/degree of freedom ( $\chi 2 / \mathrm{df}$ ) ratio, the comparative fit index (CFI), the Tucker-Lewis index (TLI), the goodness of fit index (GFI), the root means square error of approximation (RMSEA). In addition, squares structural equation modeling (SEM) was used to test empirically the proposed hypotheses. SEM is commonly used in the social sciences because of its ability to explain the relationships between unobserved constructs (latent variables) from observable variables (Henson \& Roberts., 2006). SEM is comparable to common quantitative methods, such as correlation, multiple regression, and analysis of variance to estimate and test the relationships among constructs. 


\section{Results}

\section{Descriptive statistics}

Table 3 shows a descriptive analysis (mean and standard deviation) of the data and the correlations matrix among variables. The means score for dynamic capabilities constructs (SC, LC, RC) and organizational effectiveness constructs (GA, SRA, CVA) are located between (3.38-3.80) and standard deviation (1.48-1.62) that indicates a good implementation of dynamic capabilities in enhancement organizational effectiveness in the public universities of Iraq. Also, the results show that each of the constructs is positively and significantly correlated to each other.

Table 3. Descriptive and correlation results

\begin{tabular}{|l|c|c|l|l|l|l|l|l|}
\hline & Mean & S. D & SC & LC & RC & GA & SRA & CVA \\
\hline SC & 3.38 & 1.53 & 1.000 & & & & & \\
\hline LC & 3.41 & 1.54 & $.891^{* *}$ & 1.000 & & & & \\
\hline RC & 3.53 & 1.56 & $.854^{* *}$ & $.867^{* *}$ & 1.000 & & & \\
\hline GA & 3.80 & 1.62 & $.806^{* *}$ & $.843^{* *}$ & $.844^{* *}$ & 1.000 & & \\
\hline SRA & 3.44 & 1.48 & $.778^{* *}$ & $.840^{* *}$ & $.818^{* *}$ & $.854^{* *}$ & 1.000 & \\
\hline CVA & 3.80 & 1.53 & $.671^{* *}$ & $.711^{* *}$ & $.719^{* *}$ & $.758^{* *}$ & $.733^{* *}$ & 1.000 \\
\hline
\end{tabular}

**. Correlation is significant at the 0.01 level (2-tailed).

SC=Sensing Capability, LC=learning Capability= Reconfiguring Capability, GA=Goal Approach, SRA=System Resource Approach, CVA=Competing Values Approach

Source: Authors' own research results

\section{Reliability and validity}

In this study and before testing the hypotheses reliability and validity of measurement scales were assessed by using confirmatory factor analysis (CFA), employing the statistics program AMOS 24 to estimate the face validity, convergent validity, discriminant validity and goodness of fit statistics. Face validity was established by adopting the scales from the existing literature and adapting them to the current study. The reliability of the scales was evaluated using Cronbach's alpha coefficient. As it is seen on table 2, Cronbach's alpha coefficient for all constructs ranges between 0.874 and 0.953 and it is considered acceptable which indicates that all the items are internally consistent (Hair et al., 2010). In order to determine the convergent validity, there are three important indicators of convergent validity are factor loadings (standardized estimates), Average Variance Extracted (AVE) and Composite Reliability (CR). (Hair et al., 2006) suggests that the items with loadings in between .50 to .70 can be maintained. This study investigates that the item loadings all exceeded the threshold value and statistically significant $(\mathrm{p}<0.05)$ (see table 3). Composite reliability (CR) for all constructs ranges between 0.872 and 0.955 which are above 0.50 that indicates that all the constructs have a good level of composite reliability (CR) as recommended by (Hair et al., 2012). The average variance extracted (AVE) value for all the constructs are in the range between .618 to .808 which are above the threshold value .50 which is suggested by (Hair et al., 2010).

Table 4. Constructs evaluation

\begin{tabular}{|c|c|c|c|c|c|}
\hline Constructs & $\begin{array}{c}\text { Measurement } \\
\text { Items }\end{array}$ & $\begin{array}{c}\text { Factor } \\
\text { Loading }\end{array}$ & CR & AVE & P.Value \\
\hline \multirow{3}{*}{$\begin{array}{c}\text { Sensing } \\
\text { Capability }\end{array}$} & SC1 & 0.769 & 0.767 & 0.709 & \\
\cline { 2 - 3 } & SC2 & Deleted & & & .000 \\
\cline { 2 - 3 } & SC3 & 0.769 & & & .000 \\
\cline { 2 - 3 } & SC4 & 0.915 & & & .000 \\
\cline { 2 - 3 } & SC5 & 0.876 & & & .000 \\
\hline & LC1 & 0.875 & 0.899 & 0.827 & .000 \\
\hline
\end{tabular}

Vol. 14, No. 4, Winter, pp. 402-418, ISSN 2069-8887| Management \& Marketing. Challenges for the Knowledge Society 


\begin{tabular}{|c|c|c|c|c|c|}
\hline \multirow{4}{*}{$\begin{array}{l}\text { Learning } \\
\text { Capability }\end{array}$} & LC2 & 0.871 & & & .000 \\
\hline & LC3 & 0.919 & & & .000 \\
\hline & LC4 & 0.961 & & & .000 \\
\hline & LC5 & 0.918 & & & .000 \\
\hline \multirow{5}{*}{$\begin{array}{l}\text { Reconfiguration } \\
\text { Capability }\end{array}$} & RC1 & 0.818 & \multirow[t]{5}{*}{0.837} & \multirow[t]{5}{*}{0.762} & .000 \\
\hline & $\mathrm{RC2}$ & 0.783 & & & .000 \\
\hline & RC3 & 0.938 & & & .000 \\
\hline & RC4 & 0.951 & & & .000 \\
\hline & RC5 & 0.863 & & & .000 \\
\hline \multirow[t]{4}{*}{ Goal Approach } & GA4 & 0.901 & \multirow{4}{*}{0.932} & \multirow{4}{*}{0.789} & .000 \\
\hline & GA3 & 0.837 & & & .000 \\
\hline & GA2 & 0.904 & & & .000 \\
\hline & GA1 & 0.91 & & & .000 \\
\hline \multirow{4}{*}{$\begin{array}{l}\text { System Resource } \\
\text { Approach }\end{array}$} & SRA4 & 0.883 & \multirow{4}{*}{0.872} & \multirow{4}{*}{0.632} & .000 \\
\hline & SRA3 & 0.733 & & & .000 \\
\hline & SRA2 & 0.722 & & & .000 \\
\hline & SRA1 & 0.797 & & & .000 \\
\hline \multirow{4}{*}{$\begin{array}{l}\text { Competing Values } \\
\text { Approach }\end{array}$} & CVA4 & 0.904 & \multirow{4}{*}{0.936} & \multirow{4}{*}{0.772} & .000 \\
\hline & CVA3 & 0.94 & & & .000 \\
\hline & CVA2 & 0.824 & & & .000 \\
\hline & CVA1 & 0.841 & & & .000 \\
\hline
\end{tabular}

CR =Composite Reliability and Average, AVE=Variance Extracted

Source: Authors' own research results

Discriminant validity was assessed by using two methods: First, (Fornell \& Larcker, 1981) method. He suggested that to support for discriminant validity if the square root of the AVE for a latent construct is greater than the correlation values among all the latent variables. Table (5) shows that the square root of the AVE values of all the constructs is greater than the inter-construct correlations which supports the discriminant validity of the constructs. Second, if AVE for a latent construct is larger than the maximum shared variance with other latent constructs (Hair et al., 2010). Finally, the goodness-of-fit measures were used to assess the fitness of a measurement model. The results, indicate a good model fit to the data $(\mathrm{CMIN} / \mathrm{df}=1.077$, GFI=0.973, TLI=0.998, CFI=0.999, RMSEA=0.027). Thus, the measurement model indicates a good construct validity and desirable psychometric properties.

Table 5. Discriminant validity of the constructs

\begin{tabular}{|c|c|c|c|c|c|c|c|c|}
\hline & AVE & \multicolumn{1}{|c|}{ MSV } & \multicolumn{1}{c|}{ SC } & \multicolumn{1}{c|}{ LC } & \multicolumn{1}{c|}{ RC } & \multicolumn{1}{c|}{ GA } & SRA & CVA \\
\hline SC & 0.709 & 0.697 & $\mathbf{0 . 8 4 2}$ & & & & & \\
\hline LC & 0.827 & 0.807 & 0.723 & $\mathbf{0 . 9 0 9}$ & & & & \\
\hline RC & 0.762 & 0.714 & 0.801 & 0.621 & $\mathbf{0 . 8 7 2}$ & & & \\
\hline GA & 0.789 & 0.701 & 0.721 & 0.653 & 0.812 & $\mathbf{0 . 8 8 0}$ & & \\
\hline SRA & 0.632 & 0.501 & 0.765 & 0.541 & 0.700 & 0.695 & $\mathbf{0 . 7 9 5}$ & \\
\hline CVA & 0.772 & 0.727 & 0.321 & 0.652 & 0.756 & 0.691 & 0.609 & $\mathbf{0 . 8 8 6}$ \\
\hline
\end{tabular}

Notes: Bold values in diagonal represent the squared root estimate of AVE

$\mathrm{AVE}=$ Average Variance Extracted, MSV= Maximum shared variance, $\mathrm{SC}=$ Sensing Capability, LC=learning Capability=

Reconfiguring Capability, GA=Goal Approach, SRA=System Resource Approach, CVA=Competing Values Approach Source: Authors' own research results 


\section{Test of hypotheses}

The proposed model demonstrates that dynamic capabilities constructs i.e. (sensing capability, learning capability, and reconfiguration capability) have a significant influence on organizational effectiveness. Structured equation modeling (SEM) was used to test this hypothesized model. Table (6) shows the results that (H1) is not supported, that means sensing capability has an insignificant influence on the organizational effectiveness $(\beta=-$ $0.10, \mathrm{p}<0.0854)$. The hypotheses (H2 and H3) are supported. Moreover, the positive significant influence includes, (1) learning capability and organizational effectiveness $(\beta=0.685, p<0.001)$ which means learning capability can explain positively $0.685 \%$ of the organizational effectiveness which is supporting $\mathrm{H} 2$; $(2)$ reconfiguration capability and organizational effectiveness $(\beta=0.616, p<0.001)$ that refers reconfiguration capability can explain positively $0.616 \%$ of the organizational effectiveness which confirmed H3.

Table 6. Result of hypothesis analysis

\begin{tabular}{|l|l|c|c|c|}
\hline N0. & \multicolumn{1}{|c|}{ Hypotheses } & $\begin{array}{c}\text { Beta } \\
\text { Coefficient }\end{array}$ & P.Value & Result \\
\hline H1 & $\begin{array}{l}\text { Sensing capability } \rightarrow \text { Organizational } \\
\text { effectiveness }\end{array}$ & -0.10 & 0.854 & Not Supported \\
\hline H2 & $\begin{array}{l}\text { Learning capability } \rightarrow \text { Organizational } \\
\text { effectiveness }\end{array}$ & 0.685 & 0.001 & Supported \\
\hline H3 & $\begin{array}{l}\text { Reconfiguration capability } \rightarrow \text { Organizational } \\
\text { effectiveness }\end{array}$ & 0.616 & 0.001 & Supported \\
\hline
\end{tabular}

Source: Authors' own research results

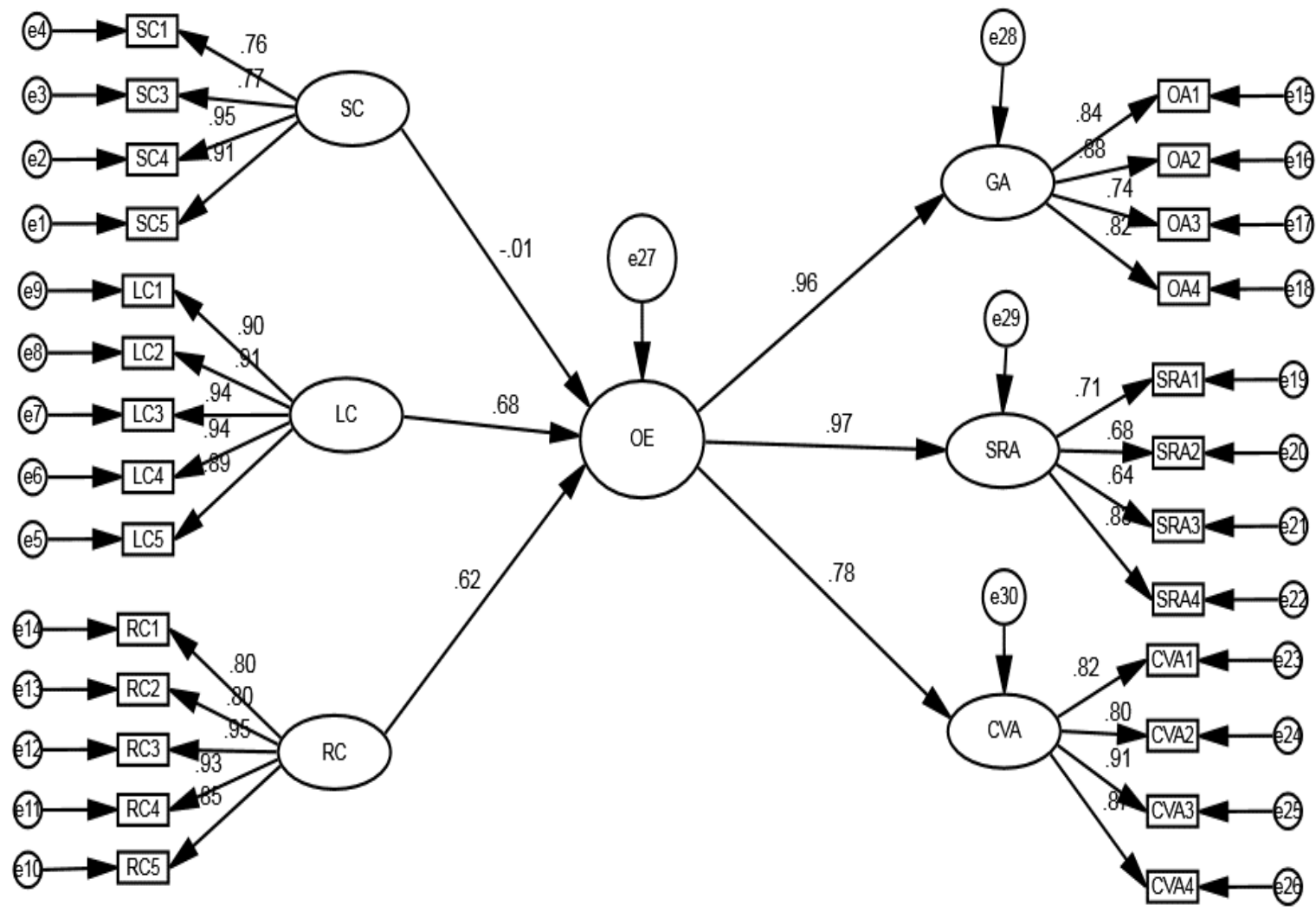

Figure 2. The SEM model analysis

\section{Discussion and conclusion}


The impact of dynamic capabilities on organizational effectiveness has been an attractive topic among scholars. However, the way that dynamic capabilities affect organizational effectiveness is still under investigation. Also, the empirical studies on this linkage are limited. The present study provides empirical evidence, which may contribute to filling this gap. The aim of this study is to investigate the influence of dynamic capabilities i.e. (sensing capability, learning capability, and reconfiguration capability) on organizational effectiveness in the Iraqi public universities context. The empirical analysis has shown several key findings: First, analytical results show that sensing capability has no significant impact on organizational effectiveness which means $\mathrm{H} 1$ is not supported. The reason underlying this may be that sensing capability impacts indirectly on organizational effectiveness. Second, the analytical results confirmed hypothesis H2 by showing that learning capability significantly affects the organizational effectiveness, which is in line with the suggestions of (Wilhelm et al.,2015) and (Helfat et al,2007). Third, the hypothesis H3 also have similar results showing that reconfiguration capability significantly and positively impacts the organizational effectiveness, which is in line with the opinion of (Teece et al.,1997) and (Eisenhardt and Martin, 2000). In conclusion, the Iraqi public universities can achieve superior organizational effectiveness by using learning capability and reconfiguring capability.

\section{Theoretical contributions of the study}

This study tries to address the gap and under-explored issues in the literature in several ways. First, the study contributes to the emerging knowledge on dynamic capabilities and the linkage between the dynamic capabilities and organizational effectiveness. Second, this study attempts to understand and empirically measure two critical managerial and organizational processes. This study determined the dynamic capabilities in three measured dimensions: sensing capability, learning capability, and reconfiguration capability which are explicit constructs. Thus, it shows that dynamic capabilities are not obscure abstractions that cannot be measured and managed, but specific processes which can be further, theoretically and empirically, explored and, in turn, to understand the nature of dynamic capabilities. Third, the study attempts to empirically test the impact of dynamic capabilities on organizational effectiveness. The findings suggest that sensing capability does not have a positive impact on organizational effectiveness while learning capability and reconfiguration capability have a positive impact on organizational effectiveness. Thus, this study provides a better understanding of the effects of dynamic capabilities.

\section{Managerial implications of the study}

In terms of managerial implications, the results of this study provide key implications for managers on how to build and develop dynamic capabilities in order to enhance organizational effectiveness. The results confirm that sensing capability does not have significant effects on organizational effectiveness while learning capability and reconfiguration capability have a significant impact on organizational effectiveness, in this case, managers should focus and put into practice the creation of learning capability and reconfiguration capability instead of sensing capability. For example, managers need to pay attention to how to acquire new knowledge and integrate it into the existing structures through learning capability and how to create new capabilities, rebuild resources and organizational structures to address the environmental turbulence through reconfiguration capability, in turn, universities will be able to achieve superior organizational effectiveness. 


\section{Limitations and future research}

Despite the significant contributions of this study but, it has some limitations that need to be addressed. First, this study focuses on the top ten Iraqi public universities context, which may not be exclusively generalizable to other sectors. Therefore; future research may investigate this phenomenon in other businesses and economic context. Second, this study adopts a cross-sectional research method for data collection, which does not allow the researcher to examine the causality of the relationships between dynamic capabilities and organizational effectiveness in greater depth. Thus, future research should aim to use longitudinal data to examine the association between dynamic capabilities and organizational effectiveness more accurately. Third, this study examined only three dimensions of dynamic capabilities the future research may include other potential dimensions. Fourth, this study examined the direct effect of dynamic capabilities on organizational effectiveness. Thus, Future research may investigate potential mediating mechanisms into a model of the dynamic capabilities- organizational effectiveness relationship.

\section{Acknowledgment}

I would like to express my sincere gratitude to my supervisor, Dr. Mezei Cecília, for her time, encouragement, and willingness to contribute her unique perspectives and knowledge to my research paper. I would like to express my thanks to my wife Hawwa Reyes for her support and encouragement also in aiding me to build more confidence in beginning my scholarly life. Without her patience and understanding, I could not have followed this path alone to make my dream come true.

\section{References}

Abu El Khair, R. H. (2016). Productive university requirements, And their relationship with Organizational effectiveness in technical colleges In Gaza governorates. Gaza: Al Azhar university.

Babelyte-Labanauske, K., \& Nedzinskas, S. (2017). DYNAMIC CAPABILITIES AND THEIR IMPACT ON RESEARCH ORGANIZATIONS' R \& $\mathrm{D}$ AND INNOVATION PERFORMANCE. Journal of Modelling in Management.

Barney, J. B. (1991). Firm resources and sustained competitive advantage. Journal of Management, Vol.17, No.1, pp. 99-120.

Barreto, I. (2010). Dynamic capabilities: A review of past research and an agenda for the future. Journal of Management, Vol. 36, No.1, pp. 256-280.

BEJINARU, R. (2017). Dynamic Capabilities of Universities in the Knowledge Economy. Management Dynamics in the Knowledge Economy, Vol.5 (2017) no.4, pp.577-595.

Capron, L. \&. (2009). Selection capability: How capability gaps and internal social frictions affect internal and external strategic renewal. Organization Science, 20(2):294312.

Carlile, P. (2004). Transferring, translating, and transforming: An integrative framework for managing knowledge across boundaries. Organization Science, 15(5): 555-568.

Chmielewski, D. P. (2007). Driving a Resource Orientation: Reviewing the Role of Resource and Capability Characteristics. Management Decision, 45, 462-483.

Creswell, J. W. (2013). research design: Qualitative, quantitative, and mixed methods approaches (2nd ed.). Thousand Oaks, CA: Sage.

Danneels, E. (2012). Second-order competences and schumpeterian rents. Strategic Entrepreneurship Journal, 6(1),42-58. 
Day, S. (2011). Closing the marketing capabilities gap. Journal of Marketing, 75 (4): 183195.

Eisenhardt, K. M., \& Martin, J. A. (2000). Dynamic capabilities: What are they? Strategic Management Journal, Vol 21, No. 10-11, pp. 1105-1121.

Fornell, C., \& Larcker, D. (1981). Structural equation models with unobservable variables and measurement error: Algebra and statistics. Journal of marketing research, pp.382-388.

Gallardo, F. O., \& Navarro, J. R. (2003). A Model of Strategic Change: Universities and Dynamic Capabilities. Higher Education Policy, V.6, NO.1, P: 1 - 14.

Galunic, D. C., \& Eisenhardt. (2001). Architectural innovation and modular corporate forms. Academy of Management Journal, 44(6): 1229-1249.

Gratton, L., \& Ghoshal, S. (2005). Beyond best practice. MIT Sloan Management Review, 46(3), 49-57.

Grohmann, A., \& Kauffeld, S. (2013). Evaluating Training Programs: Development and Correlates of the Questionnaire for Professional Training Evaluation. International Journal of Training and Development, 17, 135-155.

HAIR, J. F. (2006). Multivariate data analysis. Upper Saddle River, NJ: . Pearson Prentice Hall.

Hair, J. F. (2010). Multivariate data analysis (7th Edition ed.). Upper Saddle River. NJ: Prentice-Hall.

Hair, J., \& Sarstedt, M. R. (2012). An Assessment of the Use of Partial Least Squares Structural Equation Modeling in Marketing Research. Journal of the Academy of Marketing Science, 40, 414-433.

Helfat, C. E., \& Peteraf, M. A. (2009). Understanding dynamic capabilities: Progress along a developmental path. Strategic Organization, Vol. 7 No. 1, 91-102.

Helfat, C. F. (2007). Dynamic Capabilities: Understanding Strategic Change in Organizations. Oxford: Blackwell Publishing.

Henson, R. K., \& Roberts., J. K. (2006). Use of Exploratory Factor Analysis in Published Research Common Errors and Some Comment on Improved Practice. Educational and Psychological Measurement, 66 (3): 393-416.

Iansiti, M., \& Clark, K. (1994). Integration and dynamic capability: Evidence from product development in automobiles and mainframe computers. Industrial and Corporate Change, 3(3): 557-605.

Janssen, M., \& Castaldi, C. \&. (2015). Dynamic capabilities for service innovation: conceptualization and measurement. R\&D Management, 46 (4): 797-811.

Johara, K. (2018). Dynamic Capabilities in Times of Educational Change: The Viewpoint of School Leadership. University of Jyväskylä.

Karim, S. \&. (2016). Adding, redeploying, recombining and divesting resources and business units. Strategic Management Journal, 37(13), 54-62.

Kindström, D., \& Kowalkowski, C. a. (2013). Enabling service innovation: A dynamic capabilities approach. Journal of Business Research, 66 (8): 1063-1073.

Lavie, D. (2006). Capability reconfiguration: An analysis of incumbent responses to technological change. ACADEMY OF MANAGEMENT REVIEW, 31(1): 153-174.

Li, D. Y. (2014). Dynamic capabilities, environmental dynamism, and competitive advantage: Evidence from China. Journal of Business Research, Vol. 67, No. 1, pp. 2793-2799.

López, S. (2005). Competitive advantage and strategy formulation, The key role of dynamic capabilities. Management Decision, 43 (5-6), 661-669. 
Protogerou, A. C. (2012). Dynamic capabilities and their indirect impact on firm performance. Industrial and Corporate Change, 21(3), 615-647.

Qiang, W., \& Qile, H. \&. (2013). Explicating dynamic capabilities for corporate sustainability. EuroMed Journal of Business, 8 (3):255-272.

Rao, B. S. (2016). Effect of intellectual capital on dynamic capabilities. Journal of Organizational Change Management, Vol. 29 Iss. 2 pp.

Rastgoo, P. (2016). THE RELATIONSHIP OF TALENT MANAGEMENT AND ORGANIZATIONAL DEVELOPMENT WITH JOB MOTIVATION OF EMPLOYEES. ACTA UNIVERSITATIS AGRICULTURE ET SILVICULTURAE MENDELIANAE BRUNENSIS, Vol.64, No.2.

Rehman, K. u., \& Saeed, Z. (2015). Impact of Dynamic Capabilities on Firm Performance: Moderating Role of Organizational Competencies. Sukkur Journal of Business Administration, Volume: 2, No. 2.

RM, H., \& K., C. (1990). Architectural innovation: the reconfiguration of existing product technologies and the failure of established firms. Administrative Science Quarterly, 35: 9-30.

Schreyögg, G., \& Kliesch-Eberl, M. (2007). How dynamic can organizational capabilities be? Towards a dual-process model of capability dynamization. Strategic Management Journal, 28, pp. 913-933.

Schumacker, Randall E.\& Lomax, Richard G.(2010). A beginner's guide to structural equation modeling. Taylor \& Francis Group, New York.

Sekaran, U., \& Bougie, R. (2013). Research Methods for Business: A Skill-Building Approach. 6th Edition. New York.: Wiley.

Takahashi, A. R., \& Giacomini, E. S. (2016). Dynamic capabilities, Marketing Capability, and Organizational Performance. Brazilian Business Review, V.14, No. 5.

Teece, D. J. (2007). Explicating dynamic capabilities: the nature and micro-foundations of (sustainable) enterprise performance. Strategic management journal, Vol. 28 No.13, pp. 1319-1350.

Teece, D. J., \& Pisano, G. a. (1997). Dynamic capabilities and strategic management. Strategic Management Journal, Vol.18 No. 7, pp. 509-533.

Weng, Q., \& McElroy, J. C. (2012). Organizational career growth, affective occupational commitment, and turnover intentions. Journal of Vocational Behavior, $80,256-265$.

Wilden, R. G. (2013). Dynamic capabilities and performance: Strategy, structure, and environment. Long Range Planning, 46(1-2), 72-96.

Wilhelm, H., Schlömer, M., \& Maurer, I. (2015). How Dynamic Capabilities Affect the Effectiveness and Efficiency of Operating Routines under High and Low Levels of Environmental Dynamism. British Journal of Management.

Xueling, P. (2017). Empirical Study of Career Management and Engagement. Canadian Social Science, Vol. 13, No. 1, pp. 43-48.

Zadeha, L. K., \& Ghahremanib, M. (2016). Factors affecting organizational development (Case Study: Welfare office of East Azerbaijan province). International Academic Journal of Organizational Behavior and Human Resource Management, Vol. 3, No. 5, pp. 46-51.

Zahra, S. A. (2006). Entrepreneurship and dynamic capabilities: A review, model and research agenda. Journal of Management Studies, Vol. 43 No. 4, pp. 917-955.

Zahra, S., \& George, G. (2002). The net-enabled business innovation cycle and the evolution of dynamic capabilities. Information Systems Research, 13(2), 147-155. 
Zollo, M., \& Winter, S. G. (2002). Deliberate learning and the evolution of dynamic capabilities. Organization Science, Vol. 13 No. 3, pp. 339-351.

\section{Appendix 1: List of Measurement Items Dynamic capabilities}

\section{Sensing capability}

SC1. Our university \institute conducts environmental assessment to identify new job opportunities

SC2. Our university \institute ensures the performance assessment

SC3. our university/institute dedicates much time to applying ideas for new educational programs and improving existing educational programs

SC4. Our university \institute encourages the collaboration readiness

SC5. Our university \institute encourages the changing and renewal

2.Learning Capabilities

LC1.Our university \institute has effective routines to identify, value, and import new information and knowledge.

LC2.Our university \institute has appropriate routines to assimilate new information and knowledge.

LC3.Our university \institute has effective in transforming existing information into new knowledge.

LC4.Our university \institute has effective in utilizing knowledge in new services.

LC5.Our university \institute has effective in developing new knowledge that has the potential to influence service

3.Reconfiguration Capabilities

RC1. Our university $\backslash$ institute has a clear human resource re-allocation procedure

RC2. Our university \institute makes efforts to organizational response to environmental changes.

RC3. Our university \institute fasts response to competitor's actions.

RC4. Our university \institute has an effective communication with cooperative organization.

RC5. Our university \institute fasts response to changes in the needs of its clients

\section{Organizational effectiveness}

\section{Competing Values Approach}

CVA1. Our university $\backslash$ institute makes efforts to improve the productivity

CVA2. Our university \institute adapts to the changing environment

CVA3. Our university \institute makes efforts to the optimization of resources

CVA4. Our university \institute makes efforts to the stability

2.Goal Approach

GA1. Our university \institute ensures goal achievement

GA2. Our university \institute has an effective strategic planning

GA3. Our university $\backslash$ institute encourages the innovation

GA4. Our university \institute makes efforts improve the quality

3.System Resource Approach

SRA1. Our university $\backslash$ institute has the ability to acquire resource

SRA2. Our university \institute has good physical infrastructures and equipment

SRA3. Our university \institute ensure the accreditation

SRA4. Our university \institute encourages the organizational health 
Appendix 2: The online questionnaire link in Arabic language https://forms.gle/wuunjrgSYDNsZWzg8 